\title{
Symbolic Tools for School Administration
}

\author{
Chin-Ti Huang ${ }^{1} \&$ Hsuan-fu Ho ${ }^{1}$ \\ ${ }^{1}$ Department of Education, National Chiayi University, Taiwan \\ Correspondence: Hsuan-fu Ho, Associate Professor, Department of Education, National Chiayi University, \\ Taiwan.E-mail: hfho@mail.ncyu.edu.tw
}

Received: March 2, 2012

doi:10.5539/ass.v8n8p80

\author{
Accepted: April 13, $2012 \quad$ Published: July 1, 2012 \\ URL: http://dx.doi.org/10.5539/ass.v8n8p80
}

\begin{abstract}
Symbols are powerful tools, but since their precise functions are not readily apparent, they are often underused by school administrators. This paper thus investigates the major symbolic tools principals may use to enhance the efficiency with which they undertake their administrative responsibilities; calculates the relative degree of importance of these symbols; and explores how principals might use these tools to tackle administrative problems. Suggestions were given for school administrators to use symbols in a timely and effective manner to benefit their schools.
\end{abstract}

Keywords: symbols, symbolic tools, elementary school, principal, AHP

\section{Preface}

A rapid decrease in the number of school-age children, coupled with a declining economy, has recently forced the government of Taiwan to adopt a thorough school-consolidation policy (several schools combined into one), resulting in many students having to change schools in order to continue their studies. One unfortunate byproduct of this situation is that these new students are often treated as "outsiders" by the students who have been at the school for some time, giving rise to various conflicts. Principals generally have difficulty dealing with this problem, but some have used symbolic tools to successfully integrate students from different schools.

Symbols are powerful tools for building organizational culture - a pattern of beliefs and expectations shared by the members of an organization, which produce organizational norms and shape the behaviors of its members (Ipek, 2010). Effective leaders are skilled in the use of symbolic tools to accomplish their administrative responsibilities (Bolman \& Deal, 1991). In particular, school principals can use symbols to communicate with students, build a strong learning environment, and transmit cultural values (Furst \& Denig, 2005).

Symbols can also be used to tackle school problems caused by inadequate socialization. Many young adults have difficulty adjusting to the rapid pace of change in modern society, often resulting in antisocial behavior. Symbols help students to make sense of the ambiguous and uncertain world they live in, provide direction, increase predictability, and reduce confusion and anxiety (Bolman \& Deal, 1991).

A school's symbolic features can also enhance its identity and foster loyalty (Melewar \& Akel, 2005). The symbolic importance of campus architecture, mottos, convocations, and graduation ceremonies can be used by a school to express its commitment to a high standard of quality and, in turn, generate a sense of brand loyalty amongst students, parents, and the general public (Bosch, Venter, Han, \& Boshoff, 2006).

Despite the importance of symbolic tools, there is a serious lack of commensurate academic research in this area. This paper thus investigates the major symbolic tools principals may use to enhance the efficiency with which they undertake their administrative responsibilities; calculates the relative degree of importance of these symbols; and explores how principals might use these tools to tackle administrative problems.

\section{Review of the Related Literature}

This section begins with a definition of symbols, followed by a review of the research relating to school symbols, and finally, their application to school administration.

\subsection{Symbols}

A symbol is something used to represent some other, usually abstract, object, act, or concept. Common examples include images, icons, stories of heroic deeds, logos, myths, and rituals. Yet, symbols tend to be ambiguous, and often defy precise definition (Cohen, 1979; Bolman \& Deal, 1991; Ipek, 2010). 
Symbols are a means of expression, communication, and control, and are often combined together into a systemic or structural relationship (Meddin, 1980; Turner, 1975). To be sure, some symbols are not intentionally created, but are rather a product of social dynamics. Moreover, symbols tend to gain and shed significance over time. As vehicles carrying a load of meanings, they shape human behavior and provide a shared sense of mission and identity (Turner, 1975; Gaziel, 2003).

Symbols embody and express an organization's culture. They are both a product and a process. As a product, a symbol embodies the wisdom and experience of earlier generations. As a process, it continually renews itself to meet new needs (Bolman \& Deal, 1991).

Symbols have strong instrumental value in physical, moral, economic, and political interactions (Cohen, 1979). Symbols can perform such valuable functions as fostering loyalty, affirming legitimacy, gaining compliance, facilitating social integration, and providing organizational members with hope, security, and protection against anxiety (Baas, 2001). Symbolic rituals are used for relieving anxiety and legitimating authority (Meddin, 1980). The meaning-making strategies of framing and masking make use of symbols for crisis management (Hart, 1993). Corporate symbols such as logos and other visual design elements enhance employee commitment to the company and make it more attractive to stakeholders (Holtzhausen \& Fourie, 2008). Metaphor, humor, and entertainment-all replete with symbolic elements - help to reduce tension and pressure in an organization (Bolman \& Deal, 1991). Place-based images or logos affect customer perception by connecting an organization and its products to the traditions, history, and culture of a particular place (Rusten, Bryson, \& Aarflot, 2007).

\subsection{Symbols in School}

Kuh, Schuh, and Whitt (1991) argue that a poor quality of campus life is often the result of what takes place outside the classroom, such that it is largely beyond the control of school administrators and faculty. There are some institutions, however, which create and maintain campus climates that promote educationally purposeful behavior outside of class by using such cultural tools as a firmly developed school philosophy, well-designed activities and events, history, heroes, school traditions, and mottoes.

Apperly and Carroll (2009) constructed an experiment to examine how symbols affect children's executive function. The results indicate that symbols enable children to formulate and hold in mind a relatively complex, higher-order symbolic rule, which, in turn helps to build an efficient response strategy.

Student behavior at school is full of symbolic meaning. In order to manage their students, faculty need to understand the potent symbols embedded in student behavior. Stromberg, Nichter, and Nichter (2007) found that low-level smoking among college students carries potent symbols, and that students use smoking to accomplish social interactional goals and to structure social time and space that would otherwise be ambiguously defined.

Based on his research in an urban school in California, Staiger (2005) claims that adolescents put graffiti on school walls as a way of generating and sustaining group loyalties and channeling aggression against other groups. Teachers have to erase the graffiti time after time. Without noticing the symbolic meaning of the graffiti, this very activity will goes on. However, Korpi and Ahonen-Rainio (2010) warn that symbolic tools should be used carefully. The symbols used to ameliorate conflicts between different ethnic groups should be culturally independent and value-free, in order to be properly understood by all sides.

\subsection{Symbolic Tools for School Administration}

Demire (2007) claims that metaphors are useful tools for understanding students' experience at school. Toremen and Dos (2009) suggest that since education is a complex system, it is helpful to use metaphors to guide curriculum development and support teaching and critical thinking.

Moreover, Thornton and Jaeger (2007) claim that stories, heroes, and rituals are powerful tools that can be used by educational institutions to imbue students with a sense of civic responsibility. They surveyed students studying at the University of Virginia and the University of North Carolina, and found that symbols are the main tool for conveying to students the importance of civic responsibility.

Greenberg (2007) asserts that campus architecture makes a clear statement about the institution's self-image. The library, for example, is the core building of most universities, because of its symbolic association with knowledge. Moreover, the relationships between buildings and the overall configuration of the campus convey important messages. Similarly, Harris and Cullen (2008) claim that the arrangement of the classroom has a strong symbolic impact on students in terms of their expectations about learning and their willingness to actively engage in classroom discussion. The design of a campus should thus promote social integration, and a sense of community, and the space should be aesthetically pleasing and visually stimulating.

Hofmann (2005) emphasized that public art is a common symbolic medium on campus, and that mascots, logos, uniforms and nicknames are important ways used by a school to build its identity and a sense of solidarity among 
stakeholders. Mankin (2002) suggests that in addition to embodying and reflecting the intellectual and creative mission of a school, public art can also enhance campus aesthetics, foster community spirit, and serve to memorialize individuals or events that are significant to the school's history. Mclean and Naidoo (2007) conducted research in South Africa on how medical students regard the traditional white coat of the medical profession. They found that in addition to its practical use (identification and hygiene), the white coat is associated with a number of traditional symbolic values, including respect, dignity, reassurance, relief, hope, and happiness.

Newton and Hoyle (1994) found that the school name itself is symbolic, and that schools dealing with image problems can change the school name as a way of generating a sense of renewal. Altenhofen (2009) argues that a logo is a powerful symbolic tool, in that it functions as a form of propaganda that slowly works its way into the public consciousness, becoming engrained as part of the common culture.

\section{Methodology}

The major goals of this research were to identify the major symbolic tools that can be used by schools to enhance their effectiveness in carrying out their administration functions; to calculate their relative degree of importance; and to examine their various functions. The Analytic Hierarchy Process (AHP) was adopted as the main instrument for measuring relative importance, and correspondence analysis (CA) was employed to investigate the functions of each symbolic tool.

\subsection{The Analytic Hierarchy Process}

AHP was adopted for weighting the importance of the symbols. AHP is a way of decomposing and streamlining a complex problem and re-forming it into an organized decision hierarchy. It has several benefits: it helps to elicit opinions from experts; it helps in allocating weights to individual elements; it validates the consistency of the ratings; and, finally, it is easily combined with other techniques to perform further analysis (Saaty 1980; Cheng, Li, $\&$ Ho 2002; Davies 2001). Since AHP is the best method for calculating the relative weight of different elements, and since importance is a relative measure, rather than an objective, fixed measure, AHP is highly suited to the type of data analysis required by this research.

The approach of AHP is to break down a big problem into smaller ones. The smaller problems are relatively easier to solve, and also help clarify the subordinate relationships between each of the attributes being examined. The relative weight of each of the attributes is determined by comparing them in pairs of verbal judgments. Afterwards, pairwise comparisons are used to estimate the relative priority of the elements on each level of the hierarchy, and an eigenvector is used for assessing the consistency of the AHP structure.

In Figure 1, the main goal, located at the topmost level (on the far left), is using Symbolic Tools to attain the school's goals; the second level of the hierarchy consists of the three main dimensions of a school's symbolic features; the third level consists of the nine criteria of these three dimensions; and the fourth level consists of the 18 symbolic features that may be utilized for enhancing school efficiency.

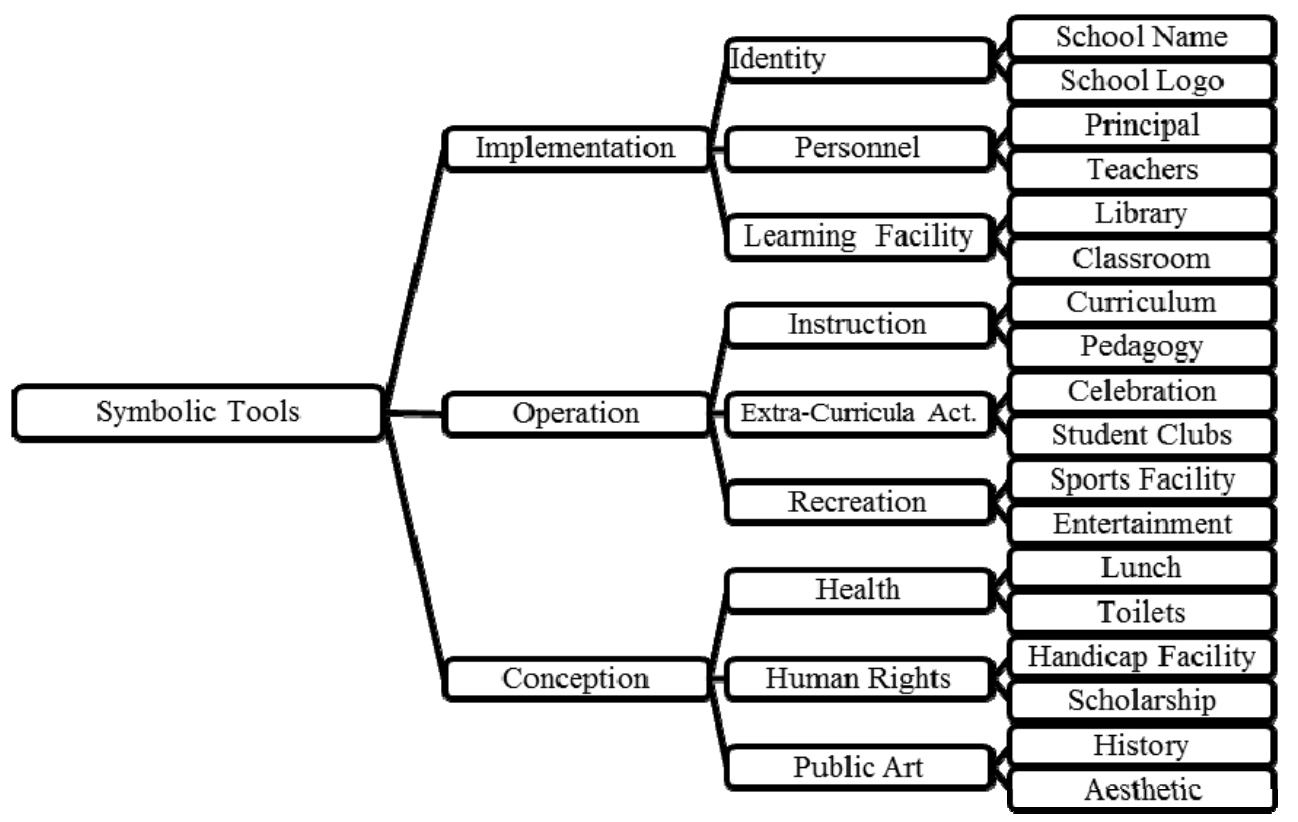

Figure 1. The AHP structure used in this research 


\subsection{Design of the Questionnaire}

A self-developed questionnaire was designed to explore the perceptions of school principals regarding the functions and relative importance of the school's symbolic features.

The questionnaire contained four parts. The first part consisted of questions about the participant's background; the second part consisted of 21 pairwise questions for AHP analysis; and in the third part the principals were asked to place a check beside the18 symbolic features they used on a regular basis. The final part consisted of a checklist comprised of the 18 symbolic features and their nine criteria. The aim was to determine the particular functions of each symbolic feature by having the participants check the appropriate boxes.

\subsection{Participants}

The questionnaire was administered to 100 school principals in Taiwan. A total of 94 questionnaires were returned, resulting in a 94 percent retrieval rate. However, in order to improve the validity, each returned questionnaire was screened by using eigenvector consistency testing, and only 67 questionnaires passed the testing.

\section{Results}

This section begins by presenting the results of AHP. This is followed by a presentation of the descriptive statistics indicating the degree to which the participants actually use these symbols in carrying out their administrative responsibilities. Finally, we present a perceptual map generated by CA to show which symbols possess which administrative functions.

\subsection{Results of $A H P$}

Microsoft Excel was adopted for the AHP procedure. Since the second-level AHP procedure contained more than two alternatives, an eigenvector consistency test was applied to confirm its validity. The CR value of the positive matrixes was 0.000 , far below the 0.1 standard suggested by Saaty (1980), thus confirming its validity. The results reveal that Implementation (.416) was the most important dimension, followed by Operation (.332) and Conception (.251).

Table 1. Weights of the three dimensions

\begin{tabular}{cclcc}
\hline First Level & CR & Second Level & Weight & Order \\
\hline \multirow{3}{*}{ Symbolic Tools } & \multirow{2}{*}{.000} & Implementation & .416 & $(1)$ \\
& & Operation & .332 & $(2)$ \\
& & Conception & .251 & $(3)$
\end{tabular}

Since all three third-level AHP procedures contained more than two alternatives, an eigenvector consistency test was applied to confirm their validity. The $\mathrm{CR}$ values of the three positive matrixes for the Implementation dimension, the Operation dimension, and the Conception dimension were $0.01,0.02$, and 0.01 respectively. Again, these values were far below the 0.1 standard, thus confirming their validity.

The results for the third level of the AHP analysis (Table 2) show that Instruction (.183) was the most important criteria, followed in descending order by Identity (.172), Personnel (.148), Health (.120), Learning Facilities (.096), Extra-curricular Activities (.080), Recreation (.066), Human Rights (.071), and Public Art (.060).

Table 2. Weights of the nine criteria

\begin{tabular}{|c|c|c|c|c|c|}
\hline $\begin{array}{l}\text { First } \\
\text { Level }\end{array}$ & $\begin{array}{c}\text { Second } \\
\text { Level }\end{array}$ & CR & $\begin{array}{l}\text { Third } \\
\text { Level }\end{array}$ & Weight & Order \\
\hline \multirow{9}{*}{$\begin{array}{c}\text { Symbolic } \\
\text { Tools }\end{array}$} & \multirow{3}{*}{ Implementation } & \multirow{3}{*}{0.01} & Identity & .172 & (2) \\
\hline & & & Personnel & .148 & (3) \\
\hline & & & Learning Facilities & .096 & $(5)$ \\
\hline & \multirow{3}{*}{ Operation } & \multirow{3}{*}{0.02} & Instruction & .183 & (1) \\
\hline & & & Extra-cur. Activities & .080 & (6) \\
\hline & & & Recreation & .066 & (9) \\
\hline & \multirow{3}{*}{ Conception } & \multirow{3}{*}{0.01} & Health & .120 & (4) \\
\hline & & & Human Rights & .071 & (7) \\
\hline & & & Public Art & .060 & (9) \\
\hline
\end{tabular}


The results of the fourth level of the AHP analysis (Table 3) indicate that the ten most important symbolic features were, in descending order, School Name (.116), Pedagogy (.106), Principal (.082), Curriculum (.082), Teachers (.066), Lunch (.060), Toilets (.059), Student Clubs (.058), School Logo (.056), and Classrooms (.055). The symbolic features considered to be less important were Handicap Facilities (.048), Sports Facilities (.043), Library (.040), Heritage (.033), Aesthetics (.027), Scholarships (.023), Entertainment (.022), and Celebrations $(.022)$.

Table 3. Weights of the 18 symbolic features

\begin{tabular}{|c|c|c|c|c|c|}
\hline First Level & Second Level & Third Level & Fourth Level & Weight & Order \\
\hline \multirow{18}{*}{$\begin{array}{l}\text { Symbolic } \\
\text { Tools }\end{array}$} & \multirow{6}{*}{ Implementation } & \multirow{2}{*}{ Identity } & School Name & .116 & (1) \\
\hline & & & School Logo & .056 & (9) \\
\hline & & \multirow{2}{*}{ Personnel } & Principal & .082 & (3) \\
\hline & & & Teachers & .066 & (5) \\
\hline & & \multirow{2}{*}{$\begin{array}{l}\text { Learning } \\
\text { Facilities }\end{array}$} & Library & .040 & (13) \\
\hline & & & Classrooms & .055 & (10) \\
\hline & \multirow{6}{*}{ Operation } & \multirow{2}{*}{ Instruction } & Curriculum & .082 & (4) \\
\hline & & & Pedagogy & .106 & (2) \\
\hline & & \multirow{2}{*}{$\begin{array}{l}\text { Extra-curricular } \\
\text { Activities }\end{array}$} & Celebrations & .022 & (18) \\
\hline & & & Student Clubs & .058 & (8) \\
\hline & & \multirow{2}{*}{ Recreation } & Sports Facilities & .043 & (12) \\
\hline & & & Entertainment & .022 & (17) \\
\hline & \multirow{6}{*}{ Conception } & \multirow{2}{*}{ Health } & Lunch & .060 & (6) \\
\hline & & & Toilets & .059 & (7) \\
\hline & & \multirow{2}{*}{ Human Rights } & Handicap Facilities & .048 & (11) \\
\hline & & & Scholarships & .023 & (16) \\
\hline & & \multirow{2}{*}{ Public Art } & Story & .033 & (14) \\
\hline & & & Aesthetics & .027 & (15) \\
\hline
\end{tabular}

\subsection{Results of the Descriptive Statistics}

In the next step we determined which of the 18 symbolic features were intentionally used by the principals on a regular basis. The percentage was obtained by dividing the number of principals who indicated that they regularly make use of a given symbolic feature by the total number of participants. The symbolic tools most frequently used by the principals, in descending order, were Curriculum (87\%), Teachers $(76 \%)$, Pedagogy (73\%), Student Clubs (69\%), Library (69\%), Celebrations (66\%), Heritage (65\%), Principal (64\%), Toilets $(64 \%)$, and Classrooms (61\%). The high frequency with which most of the symbolic tools are used indicates that the principals see them as an important part of running a school.

\subsection{Results of the Correspondence Analysis}

The final step was to use CA to produce a perceptual map which displays the special administrative functions of each of the symbolic tools. The $\mathrm{X}^{2}$ of 1162 and the $\mathrm{CR}$ value of .000 indicated that the perceptual map created by CA was feasible.

In the perceptual map (Figure 2) it can be seen that the symbolic features and administrative functions roughly form into five groups. The map shows that School Name and School Logo have the most bearing on School Identity and Distinctiveness; Teachers and Story have the most bearing on Communication and Image Construction; Lunch, Scholarships, and the Principal have the most bearing on creating a Tranquil Environment; Pedagogy, Curriculum and Celebrations have the most bearing on Stimulating Creativity and Transmitting Culture; and Classrooms, Student Clubs, and Library have the most bearing on Displaying Values and Affective Bonding. Understanding that different symbols have different functions can help principals to select in a timely manner the most appropriate symbolic tools for a given administrative purpose. 


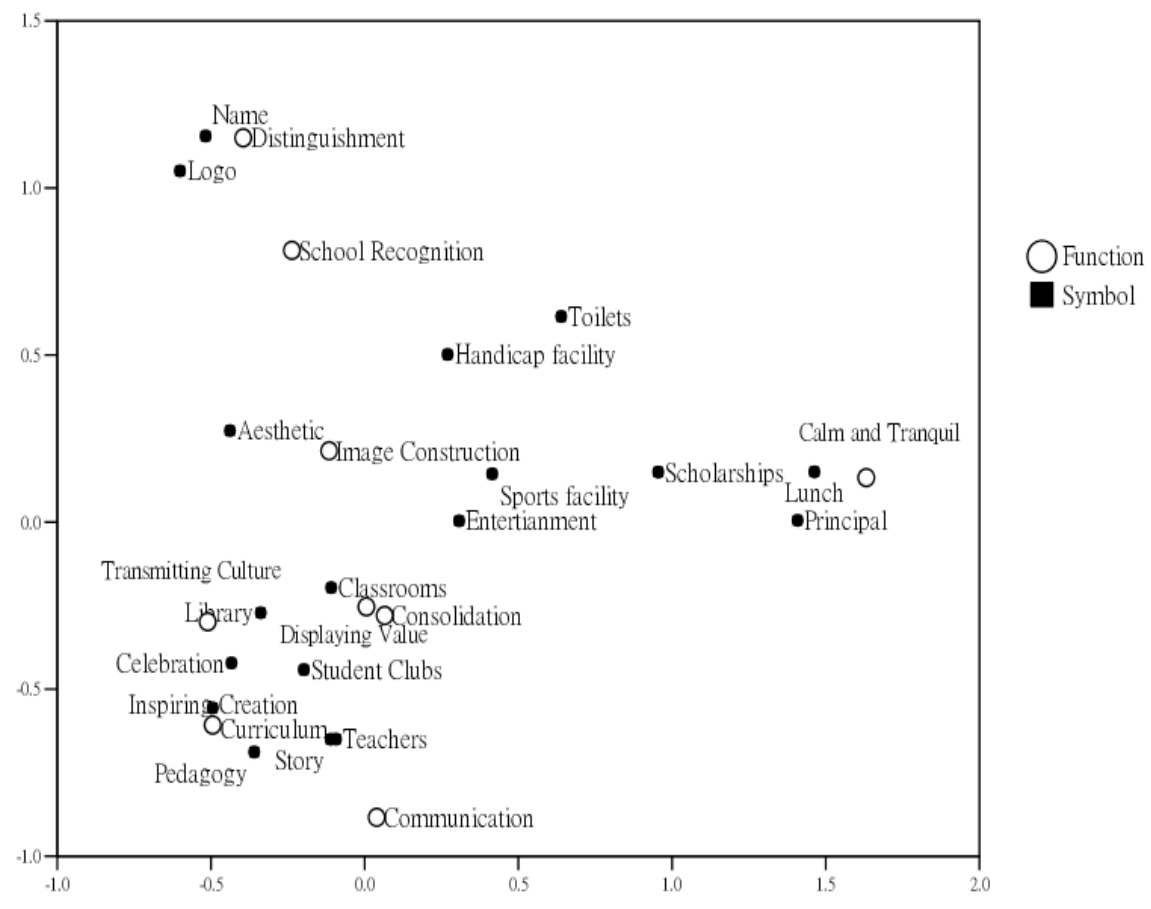

Figure 2. Perceptual map produced by CA

\section{Conclusion}

This research aimed to determine the symbolic tools which have a bearing on school administration, calculate their relative importance, determine to what extent principals actually make use them, and to determine the particular functions of these symbolic tools.

AHP was used to calculate the relative importance of the 18 symbolic features, and those weighted over .05 were School Name, School Logo, Principal, Teachers, Classrooms, Curriculum, Pedagogy, Student Clubs, Lunch, and Toilets. The implications of the findings will now be discussed.

The .116 weighting of School name shows that this is the most important symbolic feature; yet, only 58 percent of the principals have actually made use of it. In addition to representing the institution, a school's name also conveys its legal status, rights, and responsibilities, as well as its goals and mission. Not surprisingly, the related regulations make changing a school's name very difficult. Actually, the importance of a school's name can't be emphasized too much, since it represents the institution's collective success or failure. It's also a key factor for making a quick assessment of a school, either by outside parties or prospective students.

Despite its clear importance, school principals don't make sufficient use of the symbolic value of School Name. Thus it is suggested that principals make better use of their school's name to support the school's organizational goals and enhance the value of the "school brand." In particular, schools can make use of various media channels to market the school name, at the same time developing products which represent the school. For example, various types of reports help to establish a school's image. Seeing that these continuously appear in various media outlets serves to reinforce the impression the school makes on both internal and external customers, and helps to meet the requirements of the school's stakeholders.

School Logo is another underused symbolic tool. Although regarded to be rather important, it was made use of by only 57 percent of the principals in this study. A school logo represents the school and forms an important part of its image. Throughout the world, all types of groups and institutions employ a logo or emblem to convey the organization's image and spirit. In addition to their role in brand creation, logos play a key part in the development of associated products and protecting brand rights. On the one hand, the logo increases brand visibility and attracts customers; on the other hand it increases brand value. In Western nations, in addition to enterprises, schools also make continual efforts to imbue their logos with meaning and value. Yet the results of this research indicate that schools at all levels in Taiwan don't make much use of the symbolic potential of their logos. This is the most valuable finding of this study. 
It is clear that one of the chief concerns of schools at all levels in Taiwan is the shrinking number of school-age students. One way of maintaining enrollment numbers and reducing student outflow is to make better use of the school logo to increase "brand recognition" and enhance the sense of school identity. Moreover, students instilled with a sense of "brand loyalty" while at school will retain this value later on when they become parents and make decisions about which schools their children will attend. A strong school identity also helps to attract the attention of potential new students.

Another important finding was that, with a weighting of .082, the Principal is regarded as one of the key symbolic features of a school. However, it was also found that only 63 percent of the participants have actually made use of this feature in carrying out their administrative duties. Schools in Taiwan use a hierarchical system of organization in which the principal not only has final authority, but also takes responsibility for the school's success or failure. As a result, the principal's policies and leadership style have a direct influence on the school's organizational environment and its ability to meet its goals. Thus, the Principal is a symbolic feature with much potential for improving the effectiveness of school administration.

It is thus suggested that more attention be given to the Principal symbolic feature, for making better use of this symbolic tool will go far in enhancing the school's image. The many facets the Principal feature include philosophical views, educational theory and practice, professional knowledge, interpersonal relations, and personal integrity. All of these have a major bearing on a school's success or failure, and thus need to be properly addressed by either the principal or his assistants. Clearly, a firm understanding of this symbolic feature and how to use it will greatly assist a school in meeting its goals.

Also worth noting is that the Teacher symbolic feature was weighted at .066 and was actually made use of by 76 percent of the respondents. This indicates that teachers are held in high esteem and play a key role in a school's efforts to reach its goals. Without a doubt, good teachers are of utmost importance in the educational process. The results clearly indicate that the participants recognize the importance of having good teachers and taking measures to improve teacher quality.

Finally, the CA indicates that different symbolic tools have different administrative functions. Principals need to be aware of these differences and understand how to apply them to increasing the effectiveness of their school's administrative functions.

School Name and School Logo serve to establish the school's identity and distinctiveness. They also represent the school's legal status and its rights and responsibilities, at the same time serving as a constant reminder of the school's existence to both internal and external customers. This is an important part of forging a distinctive identity and establishing the school's image as a way of enhancing the school's brand value.

The Principal, Lunch and Scholarship features promote a Tranquil Environment. As the school's representative to the larger society, the principal is a key part of the school's image. The principal also leads the faculty and staff in their collective efforts to meet the school's goals, and his or her sense of clarity and confidence have a reassuring effect. As for Scholarships, by assisting disadvantaged students and encouraging gifted students, they are a gesture of goodwill which promotes a Tranquil Environment.

Pedagogy, Curriculum and Celebrations have the functions of Stimulating Creativity and Transmitting Culture. Effective pedagogy and curriculum are critical to a school's success, and there is wide agreement on the value of using pedagogical methods and curriculum development which stimulate student creativity. Holding celebrations helps to establish a school's sense of tradition and mold its distinctive culture. In Taiwan, schools at all levels hold annual anniversary celebrations and other festivities, the importance of which was made evident by the contrastive analysis.

Teachers have the most bearing on Communication and Image Construction. Teaching is a highly respectable profession, especially in Chinese cultures such as Taiwan. Even though in modern Taiwan this is not as true as it once was, teachers are still regarded as moral and ethical exemplars, a sentiment which was reflected in the results. Teaching can be seen as a process of communication in which a variety of means are used to convey information and achieve certain educational goals. Thus, teachers need to give special attention to Image Construction and Communication.

Classrooms, Student Clubs, and the Library have the most bearing on Displaying Values and Affective Bonding. For it is in Classrooms, Student Clubs, and the Library that students spend the bulk of their time and where their characters and sentiments are molded and established, as indicated by the CA. Therefore, a school need to give importance to the quality of its classrooms and library, for doing so makes clear that the school gives importance to the overall learning environment. This is a way of displaying the school's values. Student Clubs and activities 
help students to learn various skills and expand upon their formal studies. Such activities are also an important way of meeting students' social needs.

In sum, symbols are powerful tools, but since their precise functions are not readily apparent, they are often underused by school administrators. In Taiwan, although school principals have begun to utilize some symbolic tools as aids to communication, there is still little understanding of how to make use of their full potential. Moreover, it is clear that different symbolic tools have different functions, as can be seen in the perceptual map generated from the $\mathrm{CA}$ and presented above. By understanding the respective functions of the various symbolic tools at their disposal, school administrators will be able to use them in a timely and effective manner to benefit the school.

\section{References}

Altenhofen, B.J. (2009). Solace in symbols: Discovering cultural meanings in symbolic propaganda. ETC: A Review of General Semantics, 67(2), 153-163.

Apperly, I.A., \& Carroll, D.J. (2009). How do symbols affect 3- to 4-year-olds' executive function? Evidence from a reverse-contingency task. Developmental Science, 12(6), 1070-1082.

Baas, L.R. (2001). The constitution as symbol: The interpersonal sources of meaning of a secondary symbol. American Journal of Political Science, 23(1), 102-120.

Bolman, L.G., \& Deal, T. E. (1991). Reframing organizations: Artistry, choice, and leadership. San Francisco: Jossey-Bass.

Bosch, J., Venter, E., Han, Y., \& Boshoff, C. (2006). The impact of brand identity on the perceived brand image of a merged higher education institution: Part one. Management Dynamics, 15(2), 10-30.

Cohen, A. (1979). Political symbolism. Annual Review of Anthropology, 8, 87-113.

Demire, C.E. (2007). Metaphors as a reflection of middle school students' perceptions of school: A cross-cultural analysis. Educational Research and Evaluation, 13(2), 89-107.

Furst, L.G., \& Denig, S. (2005). The use of physical symbols to transmit culture in religious schools: A comparison of Adventist and Catholic schools in America. Journal of Empirical Theology, 18(1), 1-21.

Gaziel, H. (2003). Images of leadership and their effect upon school principals' performance. International Review of Education, 49(5), 475-486.

Greenberg, A. (2007). Colleges have lost interest in designing campuses with meaning. Chronicle of Higher Education, 53(25), 21-24.

Harris, M., \& Cullen, R. (2008). Renovation as innovation: Transforming a campus symbol and a campus culture. Perspective, 12(2), 47-51.

Hart, P. (1993). Symbols, rituals and power: The lost dimensions of crisis management. Journal of Contingencies and Crisis Management, 1(1), 36-50.

Hofmann, S. (2005). The elimination of indigenous mascots, logos, and nicknames. American Indian Quarterly, 29(1\&2), 156-177.

Holtzhausen, L., \& Fourie, L. (2008). Communicating to a diverse workforce: Employees' perceptions of symbolic corporate identity elements. Corporate Communication: An International Journal, 13(1), 80-94.

Ipek, C. (2010). Predicting organizational commitment from organizational culture in Turkish primary schools. Asia Pacific Education Review, 11(3), 371-385.

Korpi, J., \& Ahonen-Rainio, P. (2010). Cultural constraint in the design of pictographic symbols. The Cartographic Journal, 47(4), 351-359.

Kuh, G.D., Schuh, J.H., \& Whitt, E.J. (1991). Some good news about campus life. Change, 23(5), 48-55.

Mankin, L.D. (2002). The administration of public art on state university campuses. Journal of Arts Management, Law, \& Society, 32(1), 57-66.

Meddin, J. (1980). Symbols, anxiety, and ritual: A functional interpretation. Qualitative Sociology, 3(4), 251-271.

McLean, M., \& Naidoo, S.S. (2007). Medical students' views on the white coat: A South African perspective on ethical issues. Ethics and Behavior, 17(4), 387-402.

Melewar, T.C., \& Akel, S. (2005). The role of corporate identity in the higher education sector: A case study. Corporate Communications, 10(1), 41-57. 
Newton, S., \& Hoyle, E. (1994). Culture and survival: The role of symbol in improving the quality of a comprehensive school. School Organization, 14(3), 309-319.

Rusten, G., Bryson, J.R., \& Aarflot, U. (2007). Places through products and products through places: Industrial design and spatial symbols as sources of competitiveness. Norwegian Journal of Geography, 61, $133-144$.

Staiger, A. (2005). School walls as battle grounds: Technologies of power, space, and identify. Paedagogica Historica, 41(4\&5), 555-569.

Stromberg, P., Nichter, M., \& Nichter, M. (2007). Taking play seriously: Low-level smoking among college students. Culture, Medicine and Psychiatry, 31, 1-24.

Thornton, C.H., \& Jaeger, A.J. (2007). The ceremonies and symbols of citizenship. About Campus, 12(1), 15-20.

Toremen, F., \& Dos, I. (2009). The metaphoric perceptions of primary school teachers on the concept of inspection. Educational Sciences: Theory \& Practice, 9(4), 1999-2012.

Turner, V. (1975). Symbolic studies. Annual Review of Anthropology, 4, 145-161. 